\title{
EFFECT OF LIDOCAINE AND SUBSTANCE P ON MIGRATION AND PROLIFERATION "IN VITRO" OF HUMAN ADIPOSE DERIVED STEM CELLS (hASCS) AND BREAST CANCER CELLS (MDA-MB-231)
}

\section{Cassinello F. ${ }^{1}$, Moris L. ${ }^{2}$, López Pérez V. ${ }^{2}$, Olmedillas S. ${ }^{3}$, Villagrasa A. ${ }^{3}$, García Arranz M. ${ }^{3}$}

${ }^{1}$ Hospital Universitario Nuestra Señora de Candelaria, Dept of Anaesthesiology, Santa Cruz de Tenerife, Spain, ${ }^{2}$ Fundación Jiménez Díaz, Dept of Anaesthesiology, Madrid, Spain, ${ }^{3}$ Fundación Jiménez Díaz, New Therapies, Madrid, Spain

\section{INTRODUCTION:}

Local anaesthetics inhibit proliferation and migration while Substance P (SP) has demonstrated the opposite effect $(1,2,3)$. Local anaesthetics seem to inhibit both SP binding and the related increase in intracellular calcium (4). Our objectives were:

To demonstrate migration and proliferation inhibition induced by lidocaine of hASCs and MDA-MB-231 breast cancer cells. And to demonstrate SP can reduce the effect of lidocaine on migration and proliferation of hASCs and MDA-MB-231 breast cancer cells.

\section{METHODS:}

Cells were treated with different doses of lidocaine (4000, 10000 y $20000 \mu \mathrm{M}$ ) and/or SP (50 y 500 nM). Migration was evaluated with a wound healing scratch assay after incubation at $37^{\circ} \mathrm{C}$ and $5 \% \mathrm{CO}_{2}$ for 24 hours. The wounded area was imaged at the beginning and at 12 hours and analyzed with Image J Software. The results are shown as a percentage of remaining denuded area.

Proliferation was evaluated with AlamarBlue reagent viability assay. After 24 hours, cells were treated with different doses of lidocaine $(4000,10000$ y $2000 \mu \mathrm{M})$ and/or SP (50 y $500 \mathrm{nM}$ ).

All assays were repeated $(x 3)$ and the percentage difference between treated and control cells were calculated. Kruskall-Wallis test was used to compare mean values and $p<0,05$ considered significant.
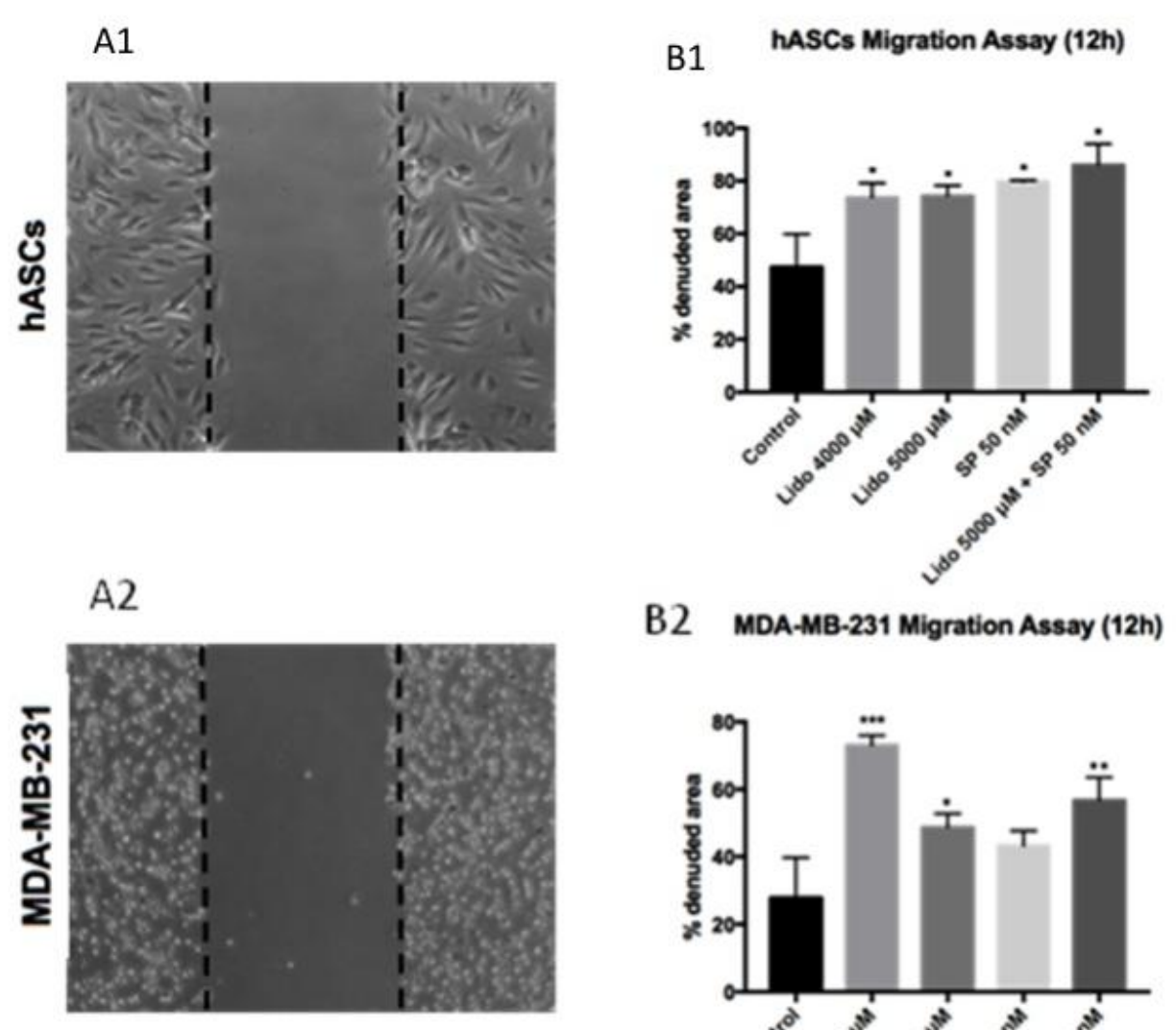

B2 MDA-MB-231 Migration Assay (12h)

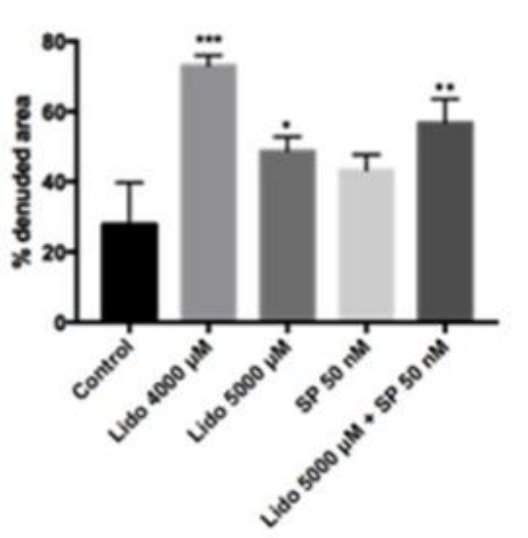

Fig.1 Migration Assay. Migration was evaluated with a wound healing scratch assay. A cell monolayer was scratched with a $100 \mu \mathrm{l}$ tip to form a wound and obtain a cell-free zone where cells at the edge can migrate and recover the wound in both cell line, hASCs (A1) and MDA-MB-231 (A2). The results are shown as a percentage of remaining denuded area. The $*$ shows the significance relative to the control group, hASCs (B1) and MDA-MB-231 (B2) ( $p$ value of $*<0.05 ; * *<0.001$ and $* * *<0.0001$ )
Table 1. Proliferation study

\begin{tabular}{|c|c|c|c|c|}
\hline \multicolumn{3}{|c|}{ hASCs } & \multicolumn{2}{c|}{ MDA-MB-231 } \\
\hline Control \% & Lido 20000 & Lido 20000+ SP 50 & Lido 20000 & Lido 20000 + SP 50 \\
\hline 100 & 30 & 66 & 30 & 62 \\
\hline 100 & 32 & 65 & 30 & 61 \\
\hline 100 & 31 & 64 & 28 & 61 \\
\hline 100 & 31 & $65^{*}$ & 29 & $61^{*}$ \\
\hline
\end{tabular}

LIDOCAINE (uM) + SP (nM) \%VIABILITY 24H. All results are media of 3 assays $(\mathrm{x} 3)$. Last line presents the average of all studies \pm SD. $\left({ }^{*} \mathrm{p}<0.05\right)$

\section{RESULTS:}

Lidocaine inhibited significantly migration at $4000 \mu \mathrm{M}$ compared with control of hASCs cells $(p=0,05)$ and also of MDA-MB-231 ( $p=0,0001)$. Substance $P$ did not influence migration alone or with lidocaine (Figure 1).

Lidocaine inhibited proliferation at $20000 \mu \mathrm{M}$ compared with control of hASCs cells $(p=0,0001)$ and also of MDA-MB-231 ( $p=0,0002)$. Adding substance $P(50 \mathrm{nM})$ reduced the inhibition effect of lidocaine on viability of hASCs cells $(p=0,03)$ and also of MDA-MB-231 $(p=0,006)$ (Table1).

\section{CONCLUSIONS:}

Lidocaine inhibited migration and proliferation.

Substance $P$ partially antagonizes the inhibition of proliferation induced by lidocaine, but does not alter the decrease on migration.

\section{References:}

Cassinello F, Prieto I, Del Olmo M, Rivas S, Strichartz G. Cancer Surgery: How may anesthesia influence outcome. Journal of Clinical Anesthesia 2015; 27: 262272.

Sakaguchi M, Kuroda Y, Hirose M. The antiproliferative effect of lidocaine on human tongue cancer cells with inhibition of the activity of epidermal growth factor receptor. Anesth Analg 2006; 102:1103-1107.

Palma C. Tachykinins and their receptors in human malignancies. Curr Drug Targets 2006;7(8):1043-52.

Li YM, Wingrove DE, Too HP, Marnerakis M, Stimson ER, Strichartz GR,et al. Local anesthetics inhibit substance $P$ binding and evoked increases in intracellular $\mathrm{Ca} 2+$. Anesthesiology 1995; 82(1):166-73. 